\title{
Integration of Value Stream Map and Strategic Layout Planning into DMAIC Approach to Improve Carpeting Process
}

\author{
Ayman Nagi ${ }^{1}$ (D), Safwan Altarazi ${ }^{2}$ \\ ${ }^{1}$ Hamburg University of Technology (Germany) \\ ${ }^{2}$ German-Jordanian University (Jordan) \\ ayman.nagi@,tubh.de, safwan.altarazi@.gju.edu.jo
}

Received: July 2016

Accepted: February 2017

\section{Abstract:}

Purpose: This paper presents an implementation of the Six Sigma DMAIC approach implementing lean tools and facilities layout techniques to reduce the occurrence of different types of nonconformities in the carpeting process. Such carpeting process can be found in several industries including construction, aviation, and automotive.

Design/methodology/approach: The improvement process was built through a sequential implementation of appropriate interconnected tools at each phase of the DMAIC approach. Utilized tools included: Pareto analysis, control charts, Ishikawa chart, 5-Whys, failure mode and effect analysis, process capability ratio, value stream map, and strategic layout planning.

Findings: The carpeting process capability, quality of the product, customer satisfaction, and cost of poor quality were significantly improved. Explicitly, the sigma level was improved from 2.297 to 2.886 and the defects per million opportunities was reduced from 21615 to 3905 .

Originality/value: This paper has demonstrated the coherent implementation of several quality tools, value stream map, and systematic layout planning within the DMAIC approach.

Keywords: carpeting process, define-measure-analyze-improve-control approach, process improvement, statistical process control, value stream map, strategic layout planning, and facilities design 


\section{Introduction}

The Six Sigma DMAIC (Define-Measure-Analyse-Improve-Control) approach has proven itself in a multitude of environments including manufacturing (Kumar \& Sosnoski, 2009; Srinivasan, Muthu, Devadasan \& Sugumaranl, 2016b) and service sectors (Antony, Antony, Kumar \& Cho, 2007; Delgado, Ferreira \& Branco, 2010), private and public (Desai \& Patel 2009) sectors, governmental (Furterer \& Elshennawy, 2005) and non-profit organizations (Cheng \& Chang, 2012), and distinct organizations and supply chains (Christopher \& Rutherford, 2004; Yang, Choi, Park, Suh \& Chae, 2007). Significant benefits have accomplished where DMAIC approach and its' associated tools were connected to an organization's problem solving and improvement activities; including reduction of excess inventory, increase equipment availability, and enhance customer value.

Carpeting is a process which can be found in various situations such as residential and commercial buildings, airplanes, and automobiles. Generally, carpeting goes through many steps as given by Figure 1 . Provided the carpet rolls, the process begins by cutting the rolls according to the specifications of the design department. The carpet piece then moves to the binding-off step where the carpet is surged using a cotton tape covered by yarn in order to protect the edges and provide a suitable positioning during alignment. Glue is then sprayed over the rear surface of the carpet roll to strengthen and provide stickiness to the roll. Afterwards, the workers focus on measuring, preparing, and cleaning the installation location (the ground) to avoid any difficulties during the installation of the carpet piece. The carpet is then laid down by the workers and fitting pieces are used in narrow areas. Based on the situation, the above steps can be accomplished manually-especially the last two steps, or automatically-mainly in the first three steps. It is worth mentioning that the above process steps are actually implemented in two distinct locations: the carpet preparation workshop and the installation site. 


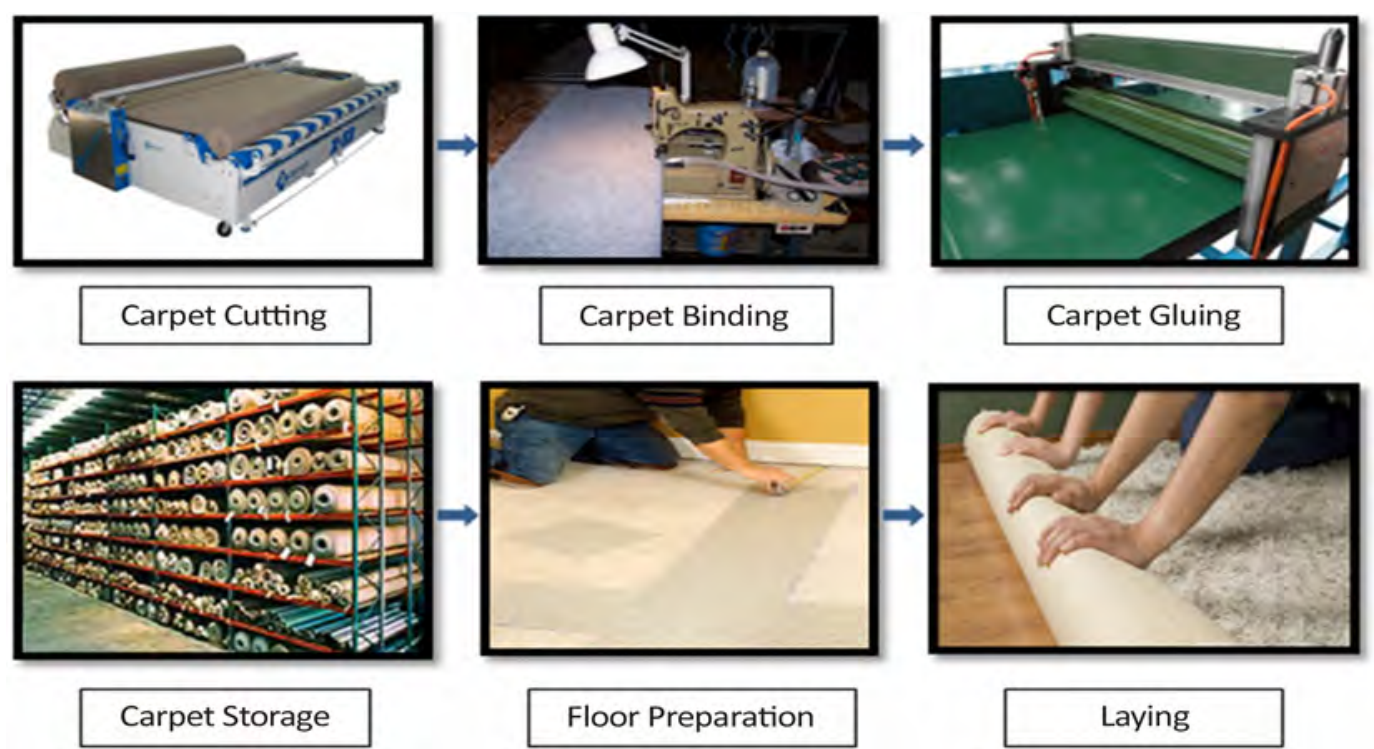

Figure 1. The carpeting preparation and installation process steps

Carpeting includes many critical-to-quality characteristics such as fitness, glueyness, and aesthetic of the installed carpet. A number of nonconformities (NCs), such as too short, too narrow, nonadjustable, or cut-out during adjustment, can rise during the process steps resulting in repeating the process; partially or fully, which cause customer dissatisfaction, high cost of poor quality, and delivery delays. This paper presents an implementation of the DMAIC approach implementing lean tools and facilities layout techniques in the carpeting process with the aim to reduce the occurrence of NCs, accordingly, reduce its non-conforming quality cost. It is worth mentioning that the studied carpeting process comprises manufacturing-belonging aspects (carpet workshop), service-based aspects (carpet installation), and a supplier-customer relationship as will be explained in section 3 .

The next section briefly reviews the literature of implementing DMAIC approach in processes' improvement. Section three presents the implementation of DMAIC approach for the carpet preparation and installation process. Finally, section four presents the work's conclusions. 


\section{Literature Review}

The DMAIC approach has been widely implemented in quality improvements projects in the last two decades. Li, Al-Refaie and Yang (2008) employed the DMAIC approach to improve the capability of surface-mount technology solder printing process by reducing thickness variations from a nominal value. X-R control charts (CCs), Analysis of Variance, and Taguchi's two step optimization were used chronologically. As a result, the process mean was adjusted very close to the target value and the $C_{\mathrm{pk}}$ process capability index was enhanced from 0.487 to 1.432 . The quality of printed circuit boards was improved using the DMAIC approach (Tong, Tsung \& Yen, 2004). After identifying and defining the problem, process capability analysis and statistical process control (SPC) tools were used to measure and analyse the original printing performance. Design of experiment (DoE), with screening optimizing stages, was then conducted to improve the sigma level of the process. Srinivasan, Muthu, Devadasan and Sugumaranl (2016a) implemented the DMAIC approach in a furnace manufacturing company, as a result, the sigma level was increased from 3.31 to 3.67. The study proved that the DMAIC approach can be implemented without the expensive Six Sigma belt-based training. Mandahawi and Obeidat (2012) implemented a customized DMAIC approach to the production process of baby diapers and found that the significant variation causes were the fluff, sap and pulp excess. After the improvement phase, the defects per million opportunities (DPMO) were reduced from 292157 to 88152.

Anderson and Kovach (2014) utilized the DMAIC approach within the lean Six Sigma methodology to reduce welding defects in a turnaround industry. As a result, the welding process was improved and the welding repair rate was reduced by more than 25\%. Vinodh, Kumar and Vimal (2014) used a lean Six Sigma framework to reduce the defects occurring in the production of a rotary switch. Main adopted tools in the DMAIC phases included project charter, value stream map (VSM), CCs, Ishikawa chart, and Taguchi factorial design. The implementation of the proposed framework showed dramatic improvement in terms of process capability, defects percentage, production lead time, and work in process inventory; hence, resulting in substantial financial savings. Franchetti (2014) developed a DMAIC-based framework for enhancing facilities capacity and reducing its cost. The framework was associated with a case study that identified at each stage of the DMAIC approach the appropriate tools to apply. The implementation of the proposed framework achieved a significant cost reduction in the facility's annual cost.

Ford's Body Six Sigma team conducted a project to solve the quality issues of the Fiesta's, a car model of Ford's floor carpeting. Formerly, the vehicle's carpet contains visible brush marks making the carpets appearance unacceptable to the customer. Quality tools like the suppliers/inputs/processes/outputs/ customers diagram, fishbone diagram, DoE, and gauge repeatability and reproducibility methodology were used in conducting the DMAIC approach. The project resulted in enhancing customer satisfaction, avoiding warranty claims, and eliminating scraps materials (Jacobsen, 2011). 
Thanks to its systematic structured phases and the variety of tools and methods that help in solving different problems efficiently; the above literature showed the DMAIC approach capability to solve quality problems in different areas. However, as indicated by Krueger, Mellat-Parast and Adams (2014), successful implementation of the approach has not been fully investigated, particularly, limited empirical studies can be found which document how lean and DMAIC, or Six Sigma, approach can be integrated (Akbulut-Bailey, Motwani \& Smedley, 2012). Chen and Lyu (2009) have also noticed that academic literature still contains few empirical studies of DMAIC approach. This paper explores the fitness of implementing several quality tools, VSM, and systematic layout planning (SLP) within the DMAIC approach framework in improving the carpeting process quality. To the best of authors' knowledge, no previous DMAIC research had integrated these tools in the way presented in this research.

\section{Implementation of the DMAIC Approach}

This section presents the detailed implementation of the DMAIC approach for the carpeting preparation and installation process stages. The implementation was conducted in an industrial environment where data was collected over a one year period and analysed mainly using Minitab software. For the Control (C) phase, additional henceforth four month's data was utilized. Various quality, lean, and facilities design tools were implemented. Figure 2 shows the sequence of the utilized tools, how the appropriate selection of these tools enables the problem solver to switch to the next DMAIC phase based on the results of the previous phase, and how the improvement process was built through the sequential implementation of appropriate interconnected tools at each phase of the DMAIC approach. Figure 2 also demonstrates the endurance aspect of the approach since each phase is feeding back the next phase resulting in initializing a new DMAIC project. The next subsections provide more details for the DMAIC approach implementation.

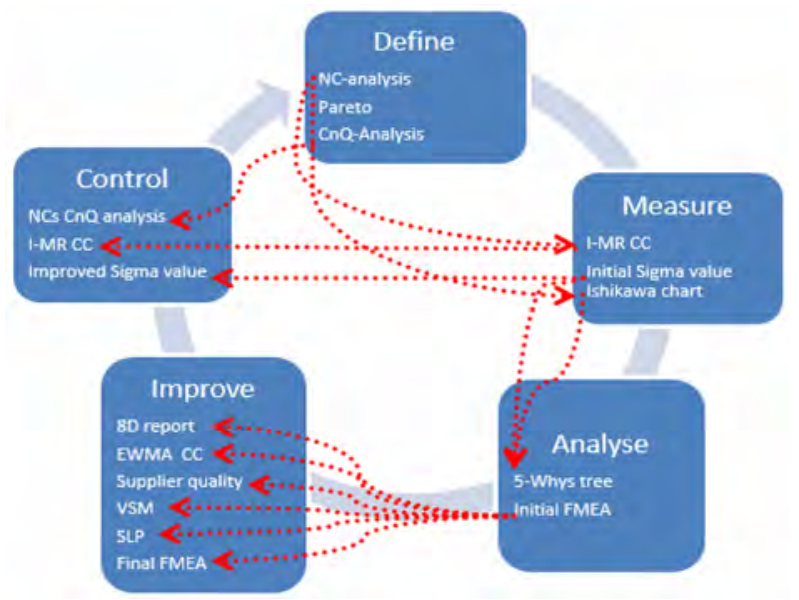

Figure 2. Summary of the implemented DMAIC approach with the utilized tools at each phase 


\subsection{Define}

Define (D) is the first phase of the DMAIC approach where a project's team clearly defines and quantifies problems through developing project's charter, estimating costs of poor quality for existing processes, determining more precisely the criteria that are critical to the customer, etc. (Neuman \& Cavanagh, 2000). In the current study, the number/types/importance of NCs in the carpeting preparation and installation stages and their cost are key issues which were worth revealed in the D phase.

\subsubsection{NCs Analysis}

83 NCs were found over the current study time span. Using Pareto charting, the NCs were divided into families as shown in Figure 3(a). The figure shows that the NC family "Not according to specification" is the main defects' family with $66 \%$ of the total NCs. Other NCs families such as "Missing", "Damages", "Polluted", came next. The family "Not according to specifications" was analyzed in details to extract further subfamilies. Figure 3(b) indicates that the major subfamilies are carpets pieces that "Does not fit", "Short", and "Narrow".

(a)

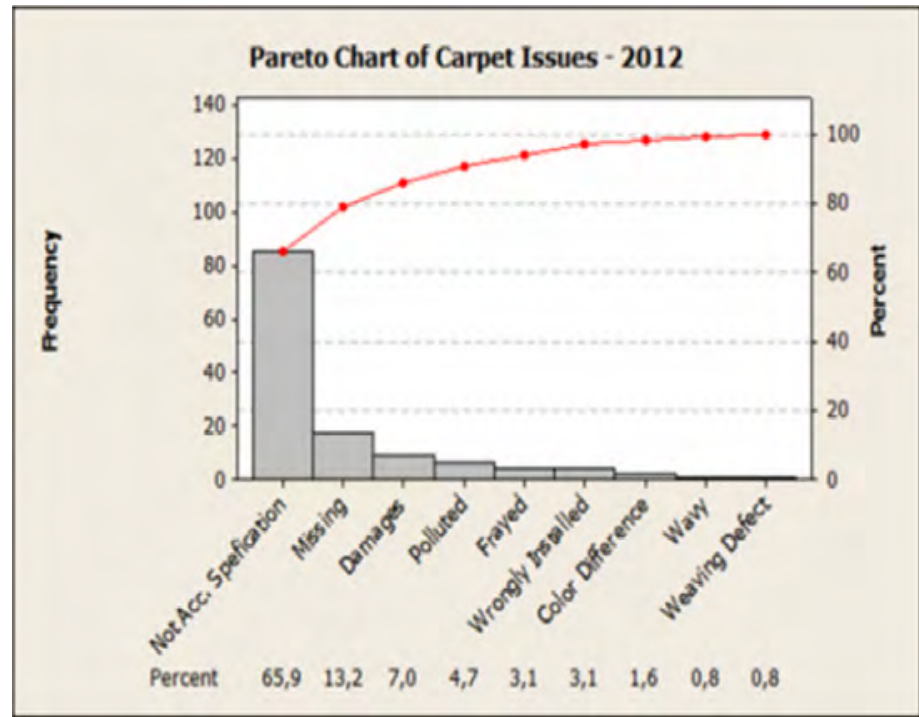


(b)

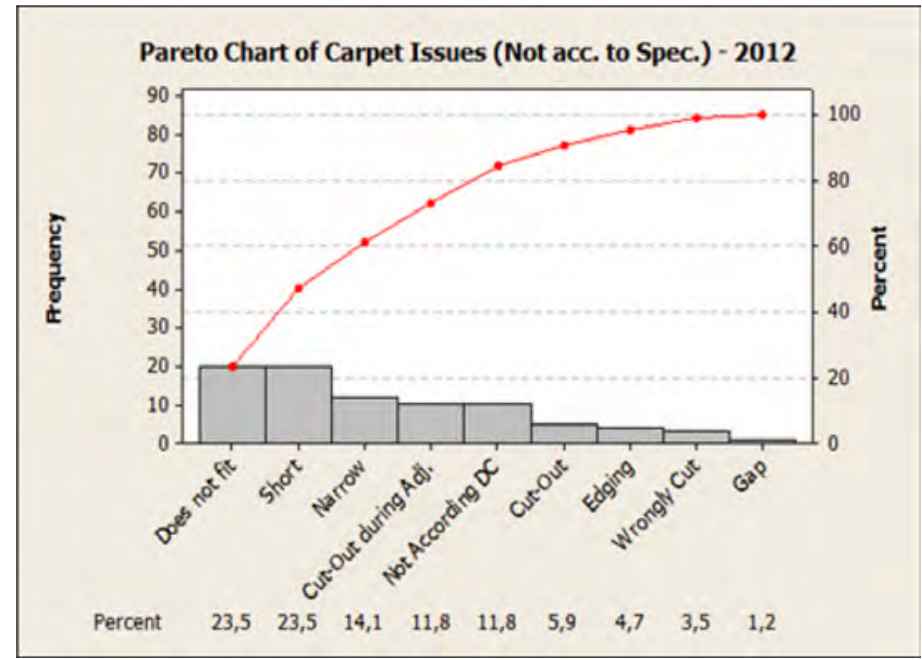

Figure 3. Pareto charts of NCs in the carpet installation: (a) all NCs, (b) "Not according to specification" family

\subsubsection{Cost of Nonconforming (CnQ)}

In order to better clarify the impact of having NCs, their cost was acquired. Table 1 presents the cost of NCs divided into administration, labor (rework hours), and material cost types. Each NC based on the defect type and size contributes to a certain amount of CnQ. It is worthy to mention that the figures of Table 1 are related only to internal CnQ. Although external CnQ do exist, because of delay in delivery which may leads to customer dissatisfaction, the external CnQ were not considered for the reason of lack of data and complexity to calculate it.

\begin{tabular}{|l|r|}
\hline Category & \multicolumn{1}{|c|}{ Cost (\$) } \\
\hline Administration & 22,644 \\
\hline Labor & 209,846 \\
\hline Material & 2,002 \\
\hline Total & 234,492 \\
\hline
\end{tabular}

Table 1. NCs costs' categories 


\subsection{Measure}

Once NCs types and their monetary effect were identified, the next step was to gather all needed information related to the carpeting process steps. This information helped in detecting the root causes of the problem in the Analysis (A) phase. Individual moving range (I-MR) Shewhart CCs, process capability analysis, and Ishikawa chart were mainly used to measure the problem's current situation.

\subsubsection{Control Charting}

Since the key cost loss of NCs was related to the "Labor" cost type as can be seen from Table 1; the time (working hours) required to fix an $\mathrm{NC}$ was selected as the critical characteristic to measure using the I-MR CCs. The I-MR was the most appropriate CCs to use since the NCs for a certain family are heterogeneous (each $\mathrm{NC}$ is detected in a different location with different characteristics,) hence, having samples of NCs was not possible neither reasonable.

A sample of $30 \mathrm{NCs}$ was chosen randomly in a chronological order from the NCs occurred during the study time period. Before control charting, the normality assumption was checked, particularly since individual CCs is sensitive to non-normality, using normal probability plotting. The data wasn't found normal; as a result, the Box-Cox transformation method was used to transform the data to normal and the appropriate value of lambda for the transformation was found to be -0.14 . The Box-Cox transformation (Box \& Cox, 1964) helps to find the optimal normalizing transformation for each variable. Through Minitab, the optimal value of lambda is automatically estimated according to the procedure described in (Osborne, 2010). The data was reviewed once more using the normal probability plot and normality was validated.

Figure 4 shows the I-MR CCs. Three out-of-control signals (points 9, 10, and 11) were detected as provided in Figure 4(a). After investigating the causes behind these data, it was found that: in sample 9 the binding-off was missing in two positions of the carpet, the carpet was short in sample 10, and the carpet in sample 11 did not fit. Having identifying the special causes of variation, the out-of-control signals were eliminated and the in-control representation of the process became as shown in Figure 4(b). These control limits were used later for monitoring in the "Control" phase. 
(a)
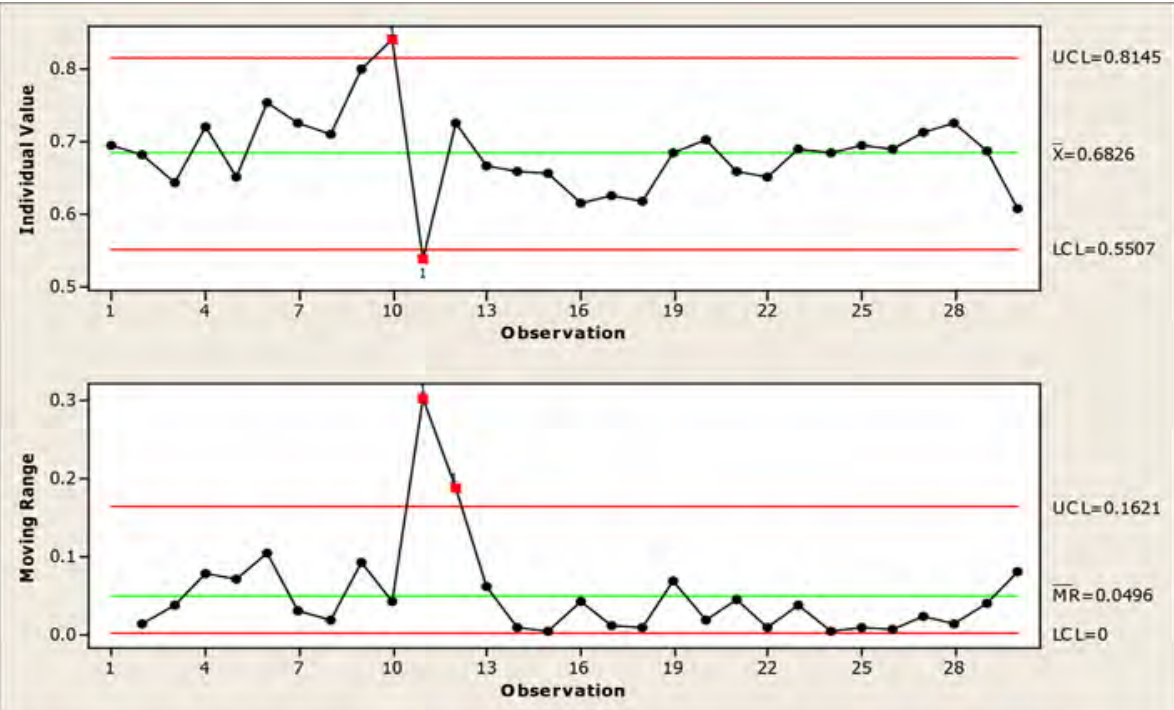

(b)
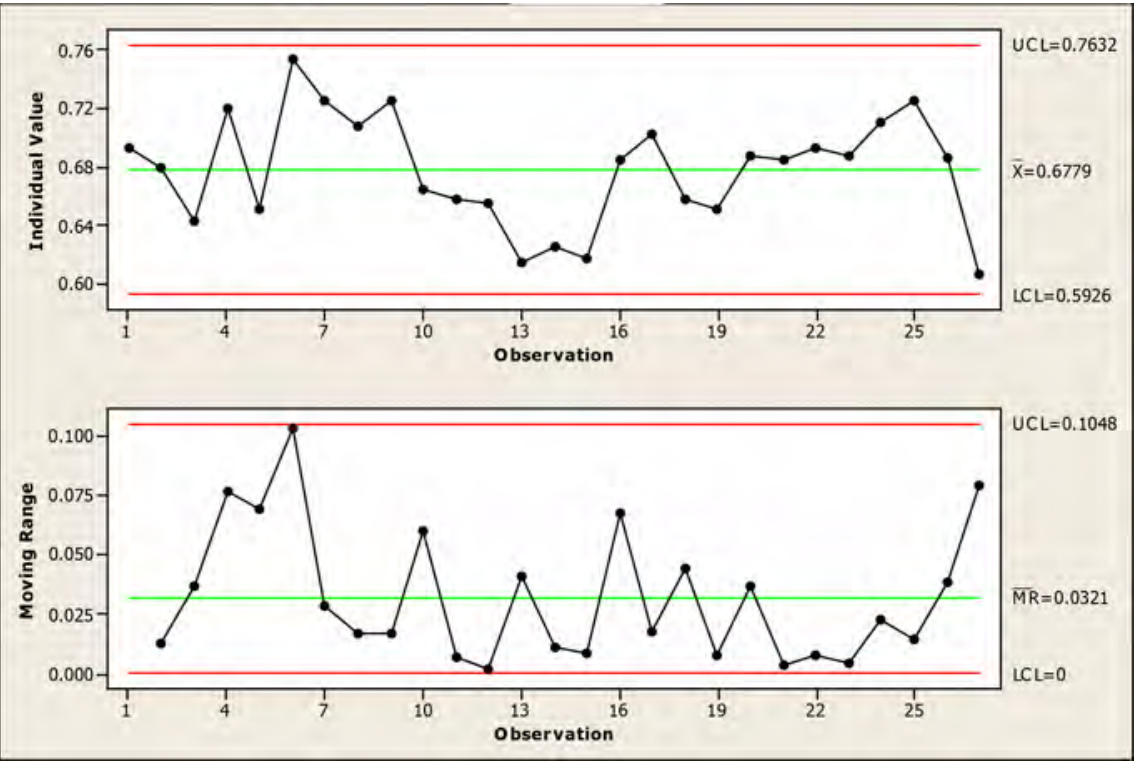

Figure 4. I-MR CCs for NCs fixing's working hours: (a) with assignable causes, (b) after eliminating the assignable causes

\subsubsection{Process Capability Analysis}

Given the attribute type of data, the DPMO followed by estimating the sigma level (also called $z$-value) were adopted to assess the capability of the process. Considering the collected data, 83 defectives were found from a sample of 1280, three key defectives' opportunities were identified (namely: shortage, color deviation and damage); accordingly, the DPMO was found to be 21615, and the z-value was calculated as 2.297 . 


\subsubsection{Ishikawa Chart}

After analyzing historical data and brainstorming with practitioners, an Ishikawa chart was created for the causes that may lead to carpet's NCs. Such causes, as indicated in Figure 5, can be due to the methods used, machines, environmental effects, calibration, material, and personnel issues. These possible causes are further investigated in the 5-Whys tool implemented in the "analyze" phase to dive deep into the root causes of the problem.

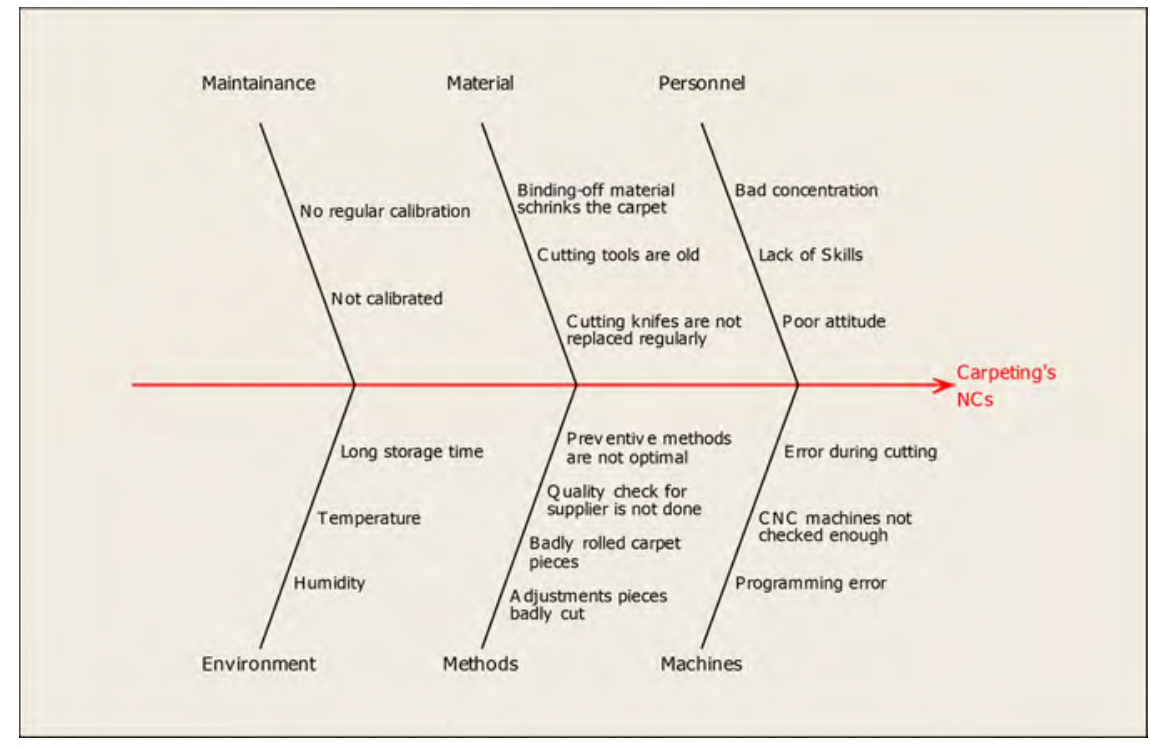

Figure 5. Ishikawa chart for carpeting process NCs

\subsection{Analyze}

In this phase, all the root causes were identified based on the information gathered in the previous phases. Additionally, the initial failure mode and effect analysis (FMEA) was established as a basis to perform the corrective actions in the Improve (I) phase.

\subsubsection{5-Whys Tree}

The 5-Whys tree enables the problem solver to discover the root causes of the problem by asking sequential questions to identify the cause-effect failure path. Each answer for the 5-Whys questions is generated after investigating and verifying if it is actually affecting the root cause or the question above of it. The answers get more precise as moving downward in the tree. Usually, the last answer is the most 
detailed root cause. In the current work, the 5-Whys activity was predeceased by identifying all stakeholders and conducting multi-functional-team meetings. In these meetings, experts were sequentially asked for their opinions regarding the root causes of NCs carpeting. The initial causes were collected from the potential causes generated by Ishikawa chart in the $\mathrm{M}$ phase. After answering all possible questions in the 5-Whys tree, the possible root causes were identified. Figure 6 shows the resulted 5-Whys tree. The first row in the tree represents the main families of the problem (Carpet shrinkage, Badly cut carpet, and Badly cut adjustment pieces). The cause/s of each family is/are answered in the second row and causes-answers chains continue until root causes are revealed. After completing the 5-Whys tree the main root causes, shaded in Figure 5, for NCs in the carpeting (preparation and installation) process steps were found to be:

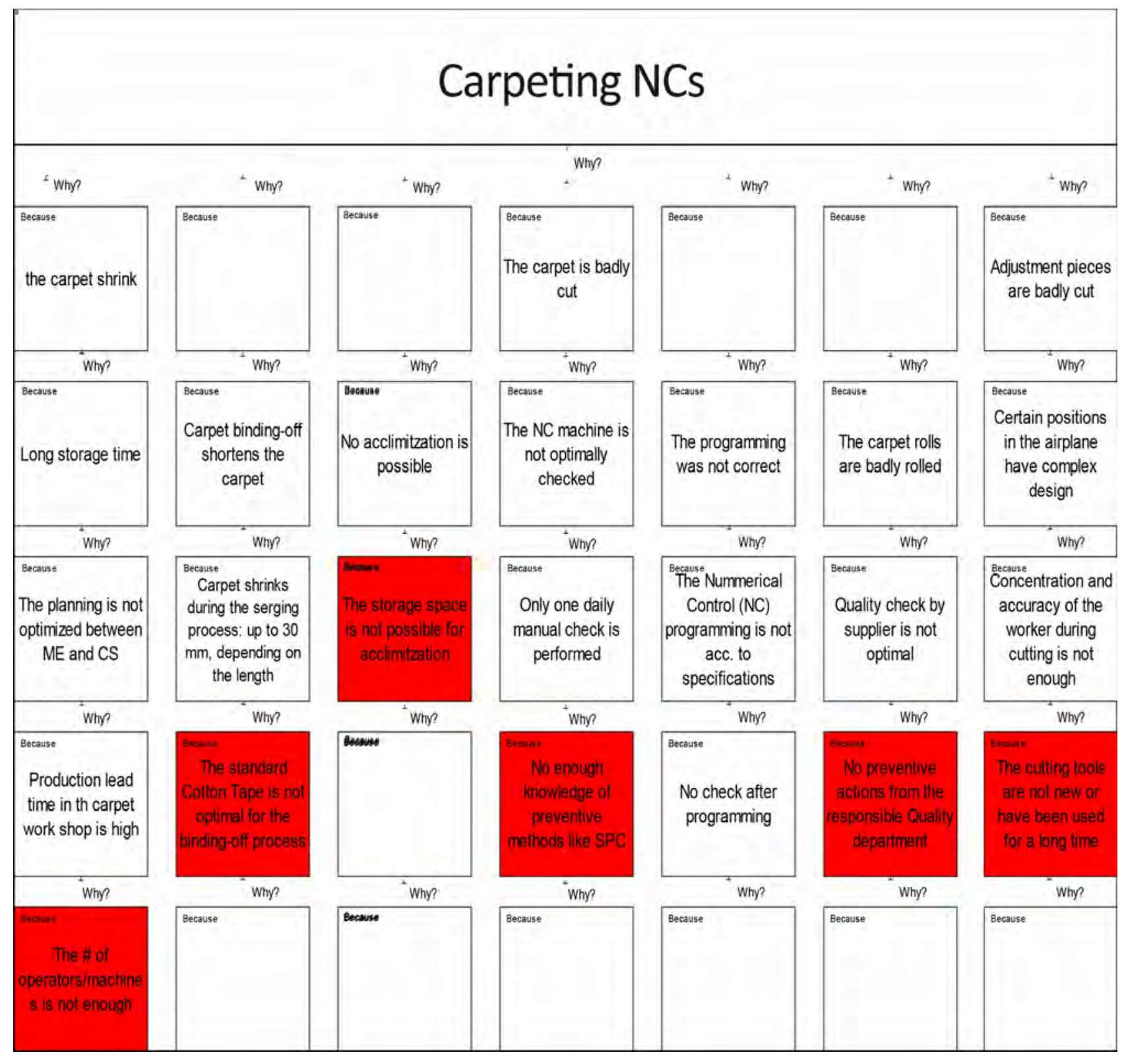

Figure 6. The 5-Whys tree for carpeting process Ncs 
1. The number of operators and machines for some activities in the carpet workshop is not adequate, hence, causing high lead times.

2. The current storage space in the carpet workshop is not enough for acclimatization activity; hence the carpet material itself is produced under stress, and therefore shrinks after cutting.

3. The daily test for the carpet cutting step, using CNC in the studied case, is not appropriate. The workers in the carpet workshop lack the SPC knowledge and practice needed to monitor the accuracy of the $\mathrm{CNC}$ machine.

4. The current cotton tape which is used in the carpet's binding step is causing shrinkage to the carpet pieces after the binding is implemented.

5. Carpet rolls of one key supplier are filled with fold gaps.

6. The cutting knifes required for cutting the adjustment pieces are not replaced frequently by workers.

\subsubsection{FMEA}

FMEA is a disciplined procedure that recognizes and prioritizes the potential failure of a product/process and the effects of that failure, identifies actions to eliminate or reduce the chance of the potential failure, and documents the process. In this work, after using the 5-Whys tree to identify the root causes, the FMEA was used to prioritize these causes. After various discussion sessions with experts, the initial FMEA was generated (initial FMEA is represented by the first 11 columns of the final FMEA given in Figure 12). Based on the risk priority number (RPN) scores, the root causes for the NCs were ranked with "Inappropriate cotton tape in the binding step" as the most critical cause and "Replacement of the cutting tools" as the least important cause.

Further analyses activities, in addition to the 5-Whys and FMEA, were conducted, such as the value steam map for the delivery process from the carpet workshop to the installation site. Yet in order to present it in a coherent way, it is integrated within the next "improve" phase.

\subsection{Improve}

The improve phase develops solutions to the root causes detected in the "analyse" phase. Accordingly, corrective actions have been implemented for the failure modes that were identified in the initial FMEA. Five main improvements activities were conducted: control charting for the cutting step, improving supplier quality, VSM for the carpet delivery, facility layout redesign for the storage space, and new 
binding-off material adoption for the binding-off step. The FMEA was updated after these improvements.

\subsubsection{Control Charting for the Cutting Step (in the Carpet Workshop)}

As can be seen from Figure 3 "Wrong cuttings" is a key defect type that causes a delay of delivery as well as high replacement cost. Many meetings with the carpet workshop's employees were conducted to discuss how to solve this defect. Control charting was the solution. Clearly, the critical-to-quality characteristic was the length of the carpet cut. The Exponentially Weighted Moving Average (EWMA) $\mathrm{CC}$ was selected for the retrospective and monitoring control charting phases. The EWMA chart was the most suitable CC for the current problem because it is the typical choice for individual data, it is very insensitive to non-normality since as it used weighted average of all past and current observations, and it is very effective in detecting small shifts (Montgomery, 2009).

The EWMA CC design parameters including the weight factor $(\lambda)$ and the multiple of sigma $(\mathrm{L})$ were set as 0.05 and 2.615 respectively. Those values were selected in order to assure high effectiveness performance of the $\mathrm{CC}$ that has low average run length (ARL) in detecting small shifts (ARL is 28.8 for a 0.5 standard deviations' shift, (Lucas \& Saccucci, 1990). Figure 7 shows a pilot run of the retrospective phase of the EWMA CC for a trial cut with $100 \mathrm{~mm}$ length. As can be seen, neither out-of-control nor non-random pattern were detected in the chart. Hence, the cutting process was considered for the monitoring phase and the EWMA CC was approved applicable to be used for other cuttings with more practical lengths.

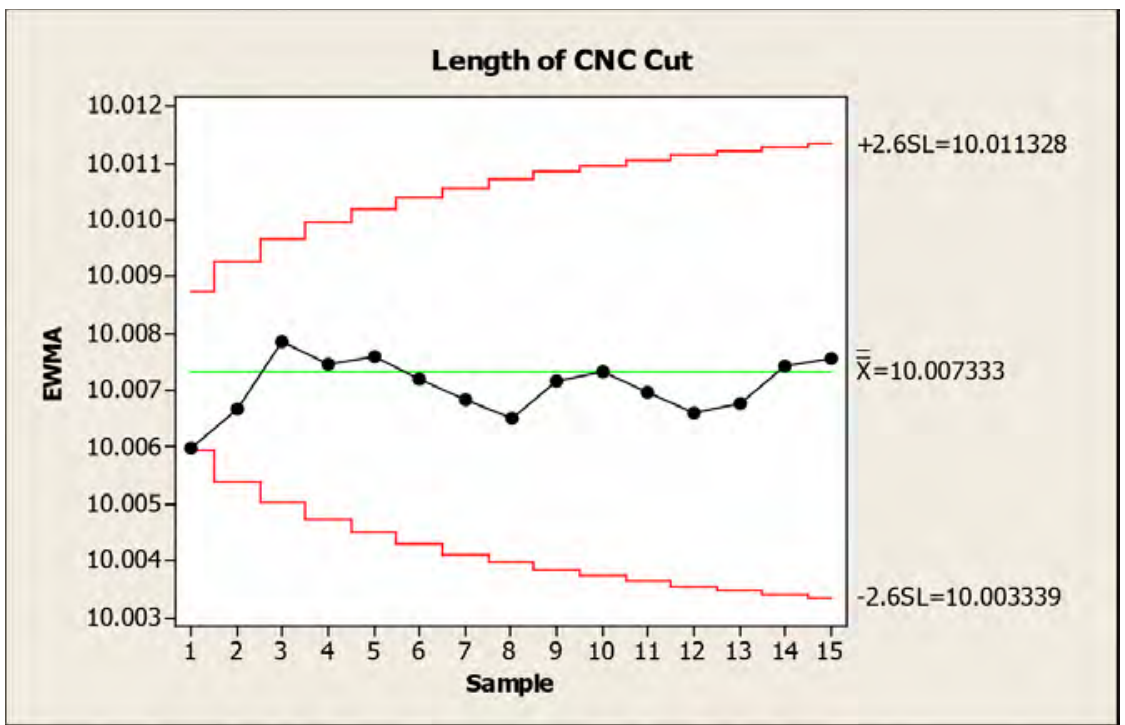

Figure 7. Pilot run for the EWMA CC for the CNC cut length 


\subsubsection{D-Report for Improving Suppliers' Quality}

In coordination with key suppliers, an 8D-Report (Eight disciplines problem solving) was used to identify and to resolve problems regarding fold gaps across the carpet. The report explained all the containment/preventive actions with all associated target dates. The preventive actions included additional inspection criteria to ensure that problems will be addressed prior leaving the supplier facility. Moreover, the report addressed improvement suggestions for the finishing process to eliminate the fold marks.

\subsubsection{VSM for Carpet Delivery}

Lengthy cycle time for the carpet delivery was found as a key potential failure. A value stream map was generated to study and analyse the lead time in delivering carpet pieces from the carpet workshop to the installation site. Actual and future VSMs in addition to an action plan for achieving the suggested future map were prepared.

Figure 8 shows the generated actual and future VSM for the carpet workshop. The actual VSM was generated by calculating the associated times for each process and work-in-process (WIP) from storage until shipping in a one-day study. As can be seen:

- The cutting/binding-off/gluing process steps take approximately $2 / 7 / 4$ hours by one/two/one operator/s to cut/bind-off/glue all the carpet rolls. Clearly, binding-off is the bottleneck step where improvements efforts should be directed.

- The setup times for the three-step process are approximately 15, 10, and 15 minutes; respectively.

- There are many WIP between the cutting step and the binding-off step due to the lengthy binding cycle time.

- There are on average 25 orders per week, which do not allow the carpet workshop to deliver the final produced carpet pieces in a lead time of less than a week.

Being the bottleneck, the number of binding-off machines and operators were suggested, and then implemented, to be increased from 2 to 4 . As a result, the total lead time (including the cutting processing time, supplier lead time, and WIP storage time) was reduced by $27 \%$. The WIP inventory was also reduced since the process, after the increase in machines and operators, became faster. Although it was not implemented, yet it is worth mentioning that further lead time reduction can be achieved by ordering an extra gluing machine for the gluing step. 
The addition of extra machines is subjected to space and cost constraints, therefore the facilities design methodology of SLP was adopted to plan the facility for the additional machines suggested by the future VSM.

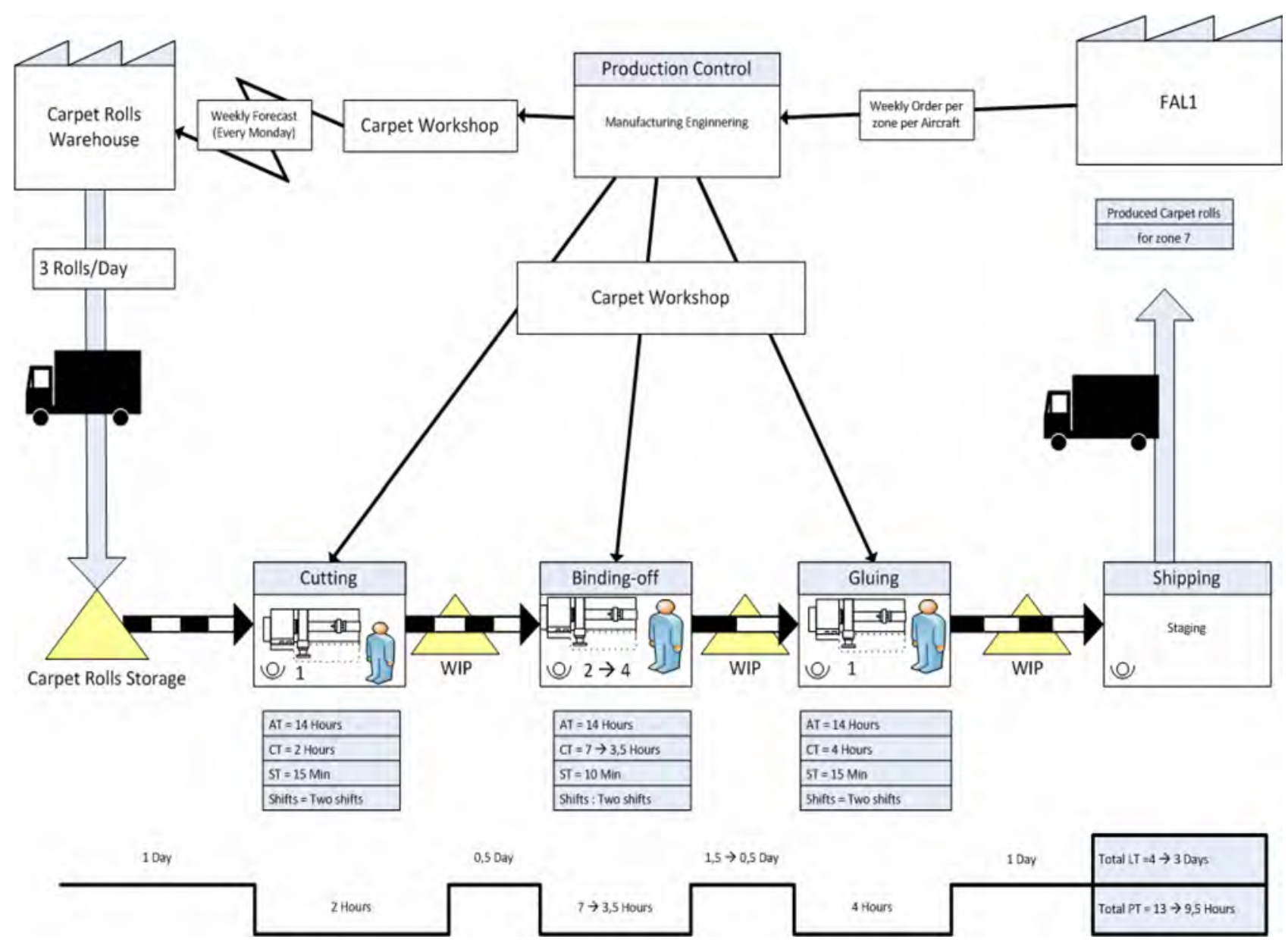

Figure 8. The actual and future VSM for the carpet workshop

\subsubsection{SLP for Facility Layout Redesign}

The current layout was analysed and improved using the SLP methodology. SLP is a tool used to arrange a workplace by locating areas with logical relationships close to each other while permitting rapid material flow with the least amount of handling, (Tompkins, 2010). In this work, the SLP was implemented as follows:

A. From-To chart: The From-To chart is a matrix, based on the actual layout of a facility, that presents the flow of material between the departments of the facility (the lower part of the cells in Figure 9), the flow of information between these department, and the distance between the departments' centroids. 
Figure 9 shows this chart for the carpet preparation workshop. For example, it was found that the material flow between the binding-off and gluing steps has "medium" relationship.

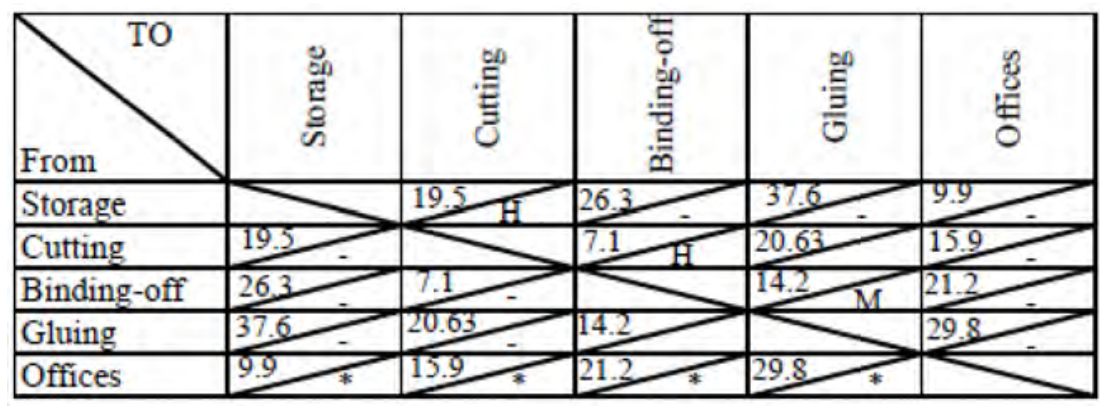

Figure 9. The workshop’s "From-To" chart (H: High Material Flow, M: Medium Material Flow, *: Information Flow)

B. Activity relationship chart: This chart helps determining how close each department should be placed to other departments. The upper part of the diamond shape represents the activity relationship rating (E, $\mathrm{I}, \mathrm{O}, \mathrm{U})$, whereas the lower part represents the rating $(1,2,3)$ reasoning. Figure 10 shows the activity relationship for the carpet workshop. For example, it is especially important to have the storage and cutting steps close to each other because of the high flow of material between them while it is unimportant for the storage to be close to the binding-off neither the gluing processing steps.

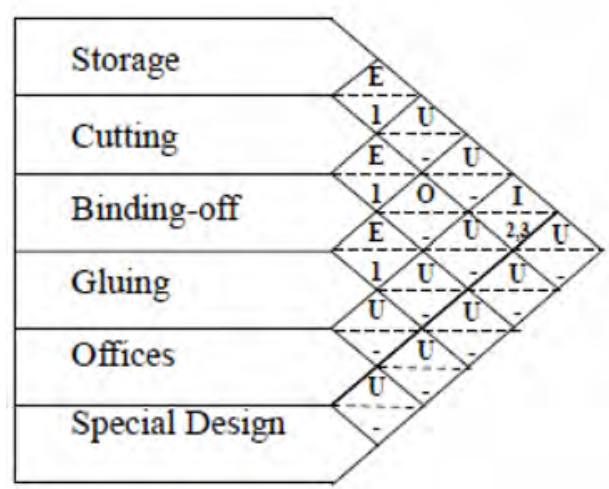

\begin{tabular}{c|l} 
Code & \multicolumn{1}{|c}{ Reason } \\
\hline 1 & Flow of Material \\
2 & Communication \\
3 & Inventory Control \\
Rating & \multicolumn{1}{|l}{ Definition } \\
\hline E & Especially Important \\
I & Important \\
O & Ordinary Closeness OK \\
U & Unimportant
\end{tabular}

Figure 10. Activity relationship chart for the carpet workshop

C. Space relationship diagram: This diagram combines the outputs from the activity relationship chart with the required departments' areas in a facility. Figure 11 shows this chart for the studied case. 


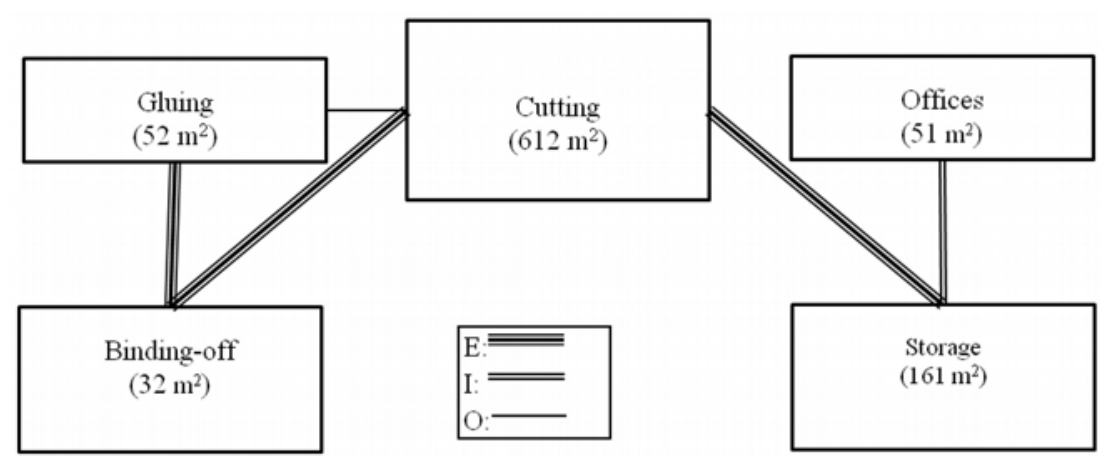

Figure 11. Space relationship diagram

Based on the above SLP steps, three different layout alternatives were raised. Table 2 summarizes the changes required to the current workshop layout (which is, because of the high variety and low volume, close to a job shop layout) by each alternative. For example, in all alternatives the storage and warehouse space is suggested to be increased from $141 \mathrm{~m}^{2}$ to $264 \mathrm{~m}^{2}$. However, the additional required new equipment and modification in the current layout differ among the three alternatives. It is worth mentioning that the three alternative layouts were generated using Microsoft Visio taking all the required changes into consideration, yet, for confidentiality reasons they are not presented here.

\begin{tabular}{|c|c|c|c|}
\hline $\begin{array}{l}\text { Layout change } \backslash \text { Layout } \\
\text { alternative }\end{array}$ & Layout I & Layout II & Layout III \\
\hline Space increase & \multicolumn{3}{|c|}{ Increase storage \& warehouse space from $141 \mathrm{~m}^{2}$ to $246 \mathrm{~m}^{2}$} \\
\hline $\begin{array}{l}\text { Additional } \\
\text { Equipment }\end{array}$ & Two Binding-off machines & $\begin{array}{l}\text { Two Binding-off machines } \\
\text { and one CNC cutting } \\
\text { machine }\end{array}$ & $\begin{array}{l}\text { Two Binding-off machines } \\
\text { and one gluing machine }\end{array}$ \\
\hline $\begin{array}{l}\text { Current space } \\
\text { modification }\end{array}$ & $\begin{array}{l}\text { - Rotate the current } \\
\text { horizontal location of the } 2 \\
\text { CNC cutting machines to } \\
\text { "vertical" to save more } \\
\text { space for the WIP } \\
\text { - Move storage close to } \\
\text { cutting }\end{array}$ & $\begin{array}{l}\text { - Move offices and changing } \\
\text { rooms to a location near } \\
\text { offices and use its old space } \\
\text { for binding-off } \\
\text { - Use the old binding-off } \\
\text { location for the new CNC } \\
\text { machine }\end{array}$ & $\begin{array}{l}\text { - Rotate the current } \\
\text { horizontal location of the } 2 \\
\text { CNC cutting machines to } \\
\text { "vertical" to save more } \\
\text { space for the WIP } \\
\text { - Move offices and changing } \\
\text { rooms to a location near } \\
\text { offices and use its old space } \\
\text { for binding-off } \\
\text { - Use the location for the } \\
\text { offices and changing rooms } \\
\text { for the new gluing machine }\end{array}$ \\
\hline
\end{tabular}

Table 2. Changes required for the suggested three layout alternatives

In order to differentiate, then select, between the three layout alternatives, a weighted multiple criteria evaluation method was implemented. The selected comparison parameters were: Total acquisition cost, 
carpet rolls that can be acclimatised, ability to reduce the total lead time, and the WIP quantity. These parameters were selected because of their importance for decision-making and their ability to be measured. Table 3 summarizes the scores of each layout under each comparison parameter along with parameters' weights. These weights were selected based on the importance of each parameter according to key stakeholders' opinions. The acquisition cost was provided from the machines suppliers. The lead time and the acclimatisation were assigned high weights while the weights for the WIP and the acquisition cost were calculated according to workers' opinions. The expanded area of the storage space, which is identical $\left(246 \mathrm{~m}^{2}\right)$ for the three layouts, enables the acclimatization of maximum 3 carpet rolls before installation. The lead time reductions for each layout as well as the amount of WIP for each layout were estimated based on the results of the VSM analysis described before.

\begin{tabular}{|l|c|c|c|}
\hline $\begin{array}{l}\text { Comparison parameters } \\
\text { with their weight }\end{array}$ & Layout I & Layout II \\
\hline Acquisition cost $(0.1)$ & $\begin{array}{c}\$ 168,580 \text { (2 binding-off } \\
\text { machines })\end{array}$ & $\begin{array}{c}\$ 918,840 \text { (2 binding-off } \\
\text { machines, } 1 \text { CNC machine) }\end{array}$ & $\begin{array}{c}\$ 523,680 \text { (2 binding-off } \\
\text { machines, } 1 \text { gluing machine) }\end{array}$ \\
\hline Carpet rolls to acclimatize $(0.3)$ & \multicolumn{3}{|c|}{3 carpet rolls } \\
\hline Lead time $(0.4)$ & 3 days & 2 days & 1 day \\
\hline WIP $(0.2)$ & low $(1)$ & medium $(2)$ & low (1) \\
\hline
\end{tabular}

Table 3. Layouts' alternatives evaluation

For the evaluation between the layouts, their scores under each parameter were normalized and added to find the simple additive weighted (SAW) score. Table 4 summarizes the SAW scores for all layouts. Since the third layout scored the highest SAW, it should be the first option for implementation. However, for budget limitations and as partial improvement, the first layout can be adopted.

\begin{tabular}{|l|r|r|r|}
\hline Parameter & Layout I & \multicolumn{1}{|c|}{ Layout II } & \multicolumn{1}{c|}{ Layout III } \\
\hline Acquisition cost & 0.1 & 0.018 & 0.032 \\
\hline Acclimatisation & 0.3 & 0.3 & 0.3 \\
\hline Lead time & 0.132 & 0.2 & 0.4 \\
\hline WIP & 0.2 & 0.1 & 0.2 \\
\hline SAW & 0.732 & 0.618 & 0.932 \\
\hline
\end{tabular}

Table 4. SAW scores for the three layout alternatives 


\subsubsection{Adopting New Binding-off Material}

The current cotton tape is causing carpet's waves during and after the stitching of the carpet. Additionally, partly caused by the wave formation, the carpet shrinks by $1-3 \%$ of the original length. In trying to solve this issue, a new binding-off material was tested. The amount of waviness using the new material was reduced and the carpet corners indicated no stress after stitching. As a result, the new material was adopted.

\subsubsection{Final FMEA Table}

After practically implementing some of the suggested improvements (control charting of the CNC cutting machine, improving the quality check by the supplier, increasing the number of operators and machines in the binding-off process, and using a new binding-off material), the FMEA was completed with assigning the target dates and the actions that should be taken. All the associated RPNs were filled after investigating the effect of the corrective action on each failure cause. The new RPNs are now less critical due to the expected improvements on each process function. Figure 12 shows the final FMEA.

\begin{tabular}{|c|c|c|c|c|c|c|c|c|c|c|c|c|c|c|c|c|c|}
\hline \# & $\begin{array}{l}\text { Process } \\
\text { Function } \\
\text { (Step) }\end{array}$ & $\begin{array}{c}\text { Potential Failure } \\
\text { Modes (process } \\
\text { defects) }\end{array}$ & Seg & $\begin{array}{l}\text { Potential Effect(s) of } \\
\text { Failure }\end{array}$ & $\begin{array}{l}\text { S } \\
E \\
V\end{array}$ & $\begin{array}{l}\text { Potential } \\
\text { Cause(s) of } \\
\text { Failure }\end{array}$ & $\begin{array}{l}0 \\
c \\
c\end{array}$ & $\begin{array}{l}\text { Current } \\
\text { Process } \\
\text { Controls }\end{array}$ & $\begin{array}{l}D \\
E \\
T\end{array}$ & $\begin{array}{l}R \\
P \\
N\end{array}$ & $\begin{array}{l}\text { Recommend } \\
\text { Actions }\end{array}$ & $\begin{array}{c}\text { Responsible } \\
\text { Person \& } \\
\text { Target Date }\end{array}$ & $\begin{array}{l}\text { Taken } \\
\text { Actions }\end{array}$ & \begin{tabular}{l|l}
$S$ & \\
$E$ & \\
$V$ &
\end{tabular} & \begin{tabular}{l|l}
0 & $D$ \\
$C$ & $E$ \\
$C$ & $T$
\end{tabular} & $\begin{array}{l}D \\
E \\
T\end{array}$ & $\begin{array}{l}R \\
P \\
N\end{array}$ \\
\hline \multirow{2}{*}{1} & \multirow{2}{*}{$\begin{array}{l}\text { NC Cutting } \\
\text { Process }\end{array}$} & \multirow{2}{*}{ Wrong cutting } & \multirow{2}{*}{ c } & \multirow{2}{*}{$\begin{array}{l}\text { 1) Shortage of the carpet } \\
\text { 2) High cost by possibsy } \\
\text { replacing the whole carpet } \\
\text { piece } \\
\text { 3) Delay of delivery }\end{array}$} & \multirow{2}{*}{8} & 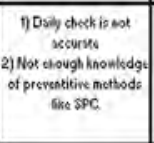 & 7 & $\begin{array}{l}\text { 1)Dashtestion the } \\
\text { NC machine }\end{array}$ & 6 & 336 & 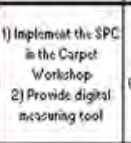 & ANogi \& CNC & 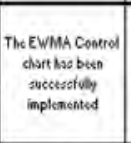 & 8 & 3 & 4 & 96 \\
\hline & & & & & & 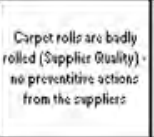 & 3 & 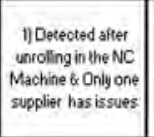 & 6 & 144 & 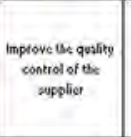 & 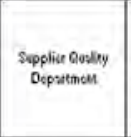 & 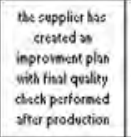 & 82 & 2 & 5 & 80 \\
\hline \multirow{2}{*}{2} & \multirow{2}{*}{$\begin{array}{l}\text { Storage \& } \\
\text { Planning Process }\end{array}$} & Long Lead tine & s & $\begin{array}{l}\text { 1) Carpet schrinks } \\
\text { 2) High cost by possibly } \\
\text { replacing the whole carpet } \\
\text { piece } \\
\text { 3) Delay of delivery }\end{array}$ & 7 & 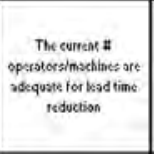 & 6 & 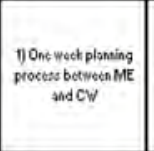 & 7 & 294 & 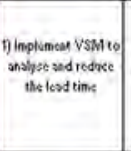 & 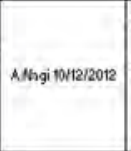 & 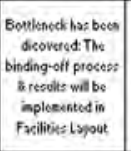 & 7 & 2 & 7 & 98 \\
\hline & & Small Storage Space & s & $\begin{array}{l}\text { 1) No accinatization is possitile } \\
\text { 2) Carpet shrinhss }\end{array}$ & 7 & 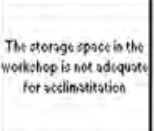 & 7 & 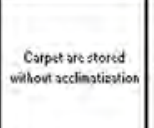 & 6 & 294 & 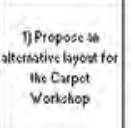 & 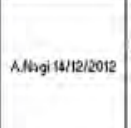 & 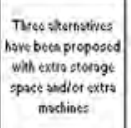 & 7 & 3 & 6 & 126 \\
\hline 3 & $\begin{array}{l}\text { Adjustment of } \\
\text { fitting pieces }\end{array}$ & $\begin{array}{l}\text { Fiting pieces are cut- } \\
\text { out during } \\
\text { adjustmerts }\end{array}$ & & $\begin{array}{l}\text { 1) High oost by ordering new } \\
\text { carpet pieces } \\
\text { 2) Time delay }\end{array}$ & 6 & 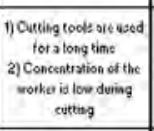 & 2 & 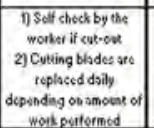 & 1 & 12 & . & . & - & - & . & - & - \\
\hline 4 & $\begin{array}{l}\text { Binding-oif } \\
\text { process }\end{array}$ & $\begin{array}{l}\text { Schrinkage of the } \\
\text { edges atter the } \\
\text { Binding-off Process }\end{array}$ & c & $\begin{array}{l}\text { 1) Schrinkage of the carpet } \\
\text { piece at the edges } \\
\text { 2) High cost by possibly } \\
\text { replacing the carpet piece } \\
\text { 3) delivery delay }\end{array}$ & 8 & 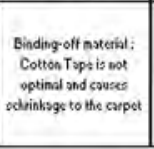 & 8 & 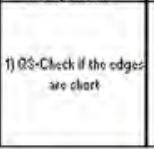 & 6 & 384 & 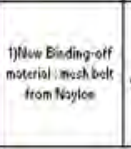 & 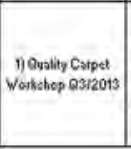 & 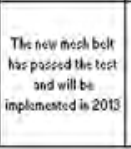 & 8 & 3 & 5 & 120 \\
\hline \multicolumn{3}{|c|}{ Sev $=$ Severe $-C=$ Cintical } & \multicolumn{8}{|c|}{ Ranges for Severity, Occurence and Detectibiby: 1 - 10} & \multicolumn{7}{|c|}{ RPN $1-1000$} \\
\hline
\end{tabular}

Figure 12. Final FMEA Table 


\subsection{Control}

Generally, the control phase aims to monitor the stability of the new improved system. It is usually related to the define phase since these two phases represent the process before and after implementing the corrective actions. In the current work, four control activities were implemented: NCs and CnQ analyses, I-MR CC for the working hours required for fixing NCs, process capability analysis, and lead time analysis. Before introducing these implements, it is worth to mention that the data for the control phase was gathered for a 4 month period after implementing the recommended improvements actions, excluding the "layout redesign".

\subsubsection{NCs and CnQ Analysis}

After implementing the corrective actions, the number of NCs and CnQ was reduced by more than 70\%. The unsolved NCs were mainly related to shrinkage of the carpet piece or to long storage time. Such NCs is expected to be significantly reduced after implementing the other mentioned corrective actions in the improve phase.

\subsubsection{Control Chart Analysis}

The transformed working hours' data (using Box-Cox transformation with Lambda $=-0.14$ ) for $14 \mathrm{NCs}$ was used to build the I-MR CCs. Figure 13 presents the I-MR CCs for both the "control" phase data and the free-assignable causes "define" phase. Since the process was changed as a result of implementing some corrective actions, new CCs limits were calculated for the "control" phase. As it can be seen, the NCs working hours of the "control phase" are in statistical control. Neither out of control signals nor non-random pattern were found in the chart. The control limits are therefore suitable for monitoring future working hours required for fixing the Ncs. 


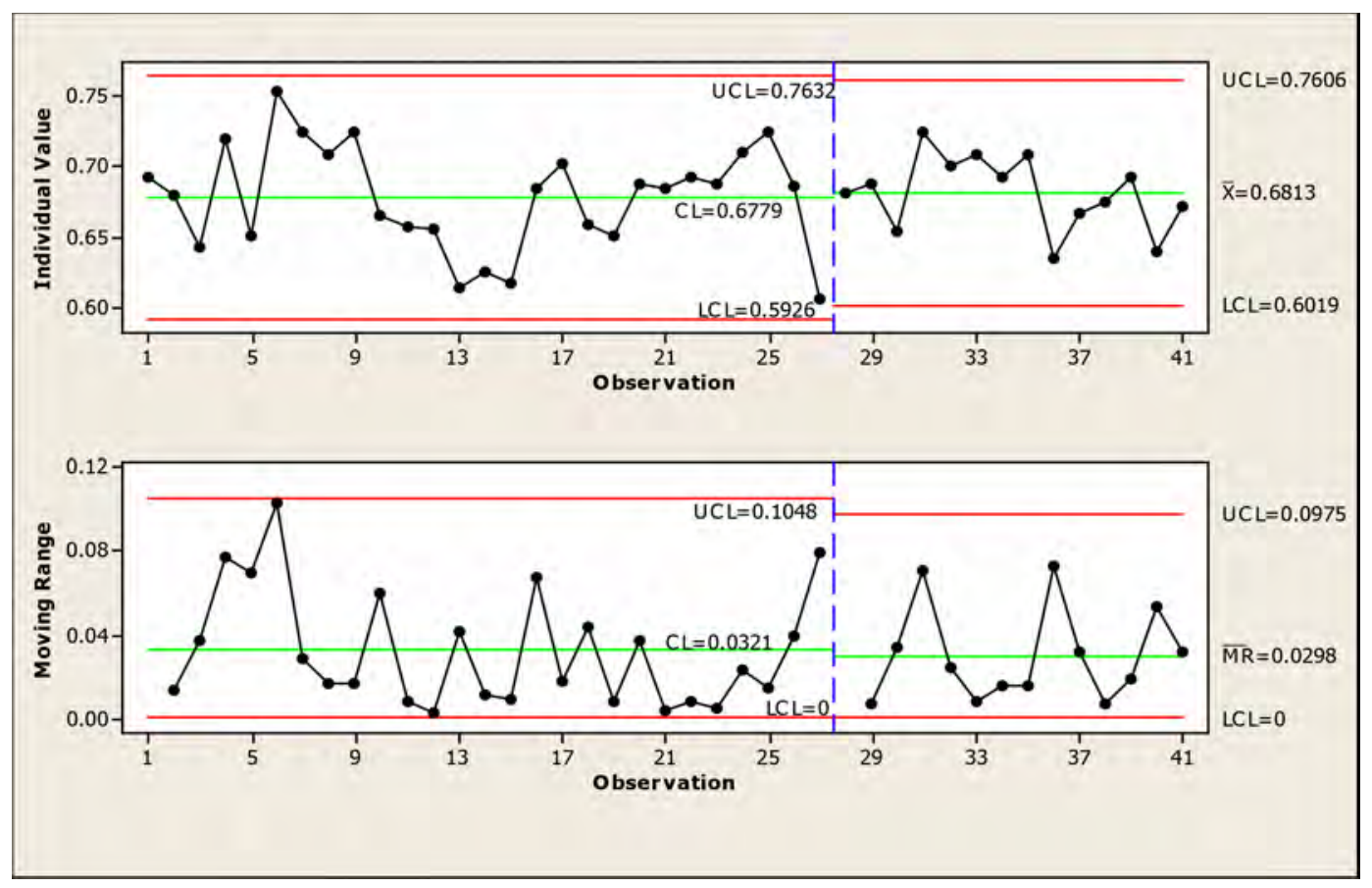

Figure 13. I-MR CCs for monitoring the NCs fixing's working hours

\subsubsection{Process Capability Analysis}

The improved DPMO was found to be 3906; accordingly the sigma level was 2.886 . These figures indeed demonstrate the significant improvement achieved after implementing three of the recommended improvement actions. More improvement is expected after implementing the "layout redesign" suggestion.

\subsubsection{Lead Time Analysis}

Table 5 compares the lead time needed to close NCs before (using a sample of $80 \mathrm{NCs}$ ) and after (using a sample of $10 \mathrm{NCs}$ ) implementing the suggested corrective actions. As demonstrated, there is a big improvement (reduction) in the lead time required for solving a single NC both in the central tendency of the time (reduction on average) and variability (lower standard deviation and range.)

\begin{tabular}{|l|r|r|}
\hline Lead time for closing an NC & Before improvements & \multicolumn{1}{|c|}{ After improvements } \\
\hline Average, standard deviation (days) & 15,10 & 6,3 \\
\hline Maximum, minimum (days) & 30,5 & 10,2 \\
\hline
\end{tabular}

Table 5. Lead time comparison for closing NCs 


\section{Conclusions}

This paper has explored the ability of the DMAIC Six Sigma approach, incorporated with VSM and SLP tools; to analyse, investigate, and remove the root causes of the carpeting (preparation-installation) process nonconformities. In the studied case, the carpeting process was improved through: implementing the EWMA control chart in the carpet workshop as a nonconformities preventative strategy, changing the workshop layout as resulted from both the VSM and SLP analyses, increasing the number of operators and machines in the binding-off process step, improving the supplier quality planning and control practices, and adopting a new binding-off material. Consequently, the carpeting process capability and hence quality of the product were improved significantly, explicitly, the process sigma level was improved from 2.297 to 2.886 and the DPMO was reduced from 21615 to 3905. Establishing a framework for incorporating facilities design techniques within the lean Six Sigma approach would be a successful extension of the current research.

\section{References}

Akbulut-Bailey, A.Y., Motwani, J., \& Smedley, E.M. (2012). When Lean and Six Sigma converge: a case study of a successful implementation of Lean Six Sigma at an aerospace company. International Journal of Technology Management, 57(1/2/3), 18-32.

Anderson, N.C., \& Kovach, J.V. (2014). Reducing welding defects in turnaround projects: A lean six sigma case study. Quality Engineering, 26(2), 168-181. https://doi.org/10.1080/08982112.2013.801492

Antony, J., Antony, F.J., Kumar, M., \& Cho, B.R. (2007). Six sigma in service organizations: Benefits, challenges and difficulties, common myths, empirical observations and success factors. International Journal of Quality \& Reliability Management, 24(3), 294-311. https://doi.org/10.1108/02656710710730889

Box, G.E., \& Cox, D.R. (1964). An analysis of transformations. Journal of the Royal Statistical Society, Series B (Methodological), 211-252.

Chen, M., \& Lyu, J. (2009). A Lean Six-Sigma approach to touch panel quality improvement. Production Planning and Control, 20(5), 445-454. https://doi.org/10.1080/09537280902946343

Cheng, C.Y., \& Chang, P.Y. (2012). Implementation of the lean six sigma framework in non-profit organizations: A case study. Total Quality Management \& Business Excellence, 23(3/4), 431-447. https://doi.org/10.1080/14783363.2012.663880 
Christopher, M., \& Rutherford, C. (2004). Creating supply chain resilience through agile Six Sigma. Critical Eye, 7(1), 24-28.

Delgado, C., Ferreira, M., \& Branco, M.C. (2010). The implementation of lean Six Sigma in financial services organizations. Journal of Manufacturing Technology Management, 21(4), 512-523.

https://doi.org/10.1108/17410381011046616

Desai, D., \& Patel, M. (2009). Impact of Six Sigma in a developing economy: analysis on benefits drawn by Indian industries. Journal of Industrial Engineering and Management, 2(3), 517-538.

https://doi.org/10.3926/jiem.2009.v2n3.p517-538

Franchetti, M. (2014). Continuous improvement and facility redesign through the lean DMAIC Six Sigma approach: a final assembly work unit case study from Ohio, USA. International Journal of Six Sigma and Competitive Advantage, 8(2), 83-94. https://doi.org/10.1504/IJSSCA.2014.064253

Furterer, S., \& Elshennawy, A.K. (2005). Implementation of TQM and lean Six Sigma tools in local government: a framework and a case study. Total Quality Management \& Business Excellence, 16(10), 1179-1191. https://doi.org/10.1080/14783360500236379

Jacobsen, J. (2011). Ford Team Project Builds Relationships, Improve Quality. http://krytonmetals.com/wpcontent/uploads/ford-team-project-builds-relationships.pdf (Accessed: July 2016).

Krueger, D.C., Mellat-Parast, M., \& Adams, S. (2014). Six Sigma implementation: a qualitative case study using grounded theory. Production Planning and Control, 25(10), 873-889.

https://doi.org/10.1080/09537287.2013.771414

Kumar, S., \& Sosnoski, M. (2009). Using six sigma DMAIC to systematically improve shopfloor production quality and costs. International Journal of Productivity and Performance Management, 58(3), 254-273. https://doi.org/10.1108/17410400910938850

Li, M.H., Al-Refaie, A., \& Yang, C.Y. (2008). DMAIC approach to improve the capability of SMT solder printing process. IEEE Transactions on Electronics Packaging Manufacturing, 31(2), 126-133. https://doi.org/10.1109/TEPM.2008.919342

Lucas, J.M., \& Saccucci, M.S. (1990). Exponentially weighted moving average control schemes: properties and enhancements. Technometrics, 32(1), 1-12. https://doi.org/10.1080/00401706.1990.10484583

Mandahawi, N., \& Obeidat, S.M. (2012). Six sigma implementation to minimise weight variation for Baby Lido Diaper manufacturing company. International Journal of Six Sigma and Competitive Advantage, 7(2/3/4), 243-255. https://doi.org/10.1504/IJSSCA.2012.053472 
Montgomery, D.C. (2009). Introduction to statistical quality control ( $6^{\text {th }}$ ed.). New York: Wiley.

Neuman, R.P., \& Cavanagh, R. (2000). The six sigma way: How GE, Motorola, and other top companies are honing their performance. New York: McGraw-Hill.

Tompkins, J.A. (2010). Facilities planning (4 ${ }^{\text {th }}$ ed.). New York: Wiley.

Osborne, J.W. (2010). Improving your data transformations: Applying the Box-Cox transformation. Practical Assessment, Research and Evaluation, 15(12), 1-9.

Srinivasan, K., Muthu, S., Devadasan, S.R., \& Sugumaran, C. (2016a). Enhancement of sigma level in the manufacturing of furnace nozzle through DMAIC approach of Six Sigma: a case study. Production Planning and Control, 27(10), 810-822. https://doi.org/10.1080/09537287.2016.1143130

Srinivasan, K., Muthu, S., Devadasan, S.R., \& Sugumaran, C. (2016b). Six Sigma through DMAIC phases: a literature review. International Journal of Productivity and Quality Management, 17(2), 236-257. https://doi.org/10.1504/IJPQM.2016.074462

Tong, J.P.C., Tsung, F., \& Yen, B.P.C. (2004). A DMAIC approach to printed circuit board quality improvement. The International Journal of Advanced Manufacturing Technology, 23(7/8), 523-531. https://doi.org/10.1007/s00170-003-1721-z

Vinodh, S., Kumar, S. V., \& Vimal, K.E.K. (2014). Implementing lean sigma in an Indian rotary switches manufacturing organisation. Production Planning \& Control, 25(4), 288-302. https://doi.org/10.1080/09537287.2012.684726

Yang, H.M., Choi, B.S., Park, H.J., Suh, M.S., \& Chae, B.K. (2007). Supply chain management Six Sigma: A management innovation methodology at the Samsung Group. Supply Chain Management: An International Journal, 12(2), 88-95. https://doi.org/10.1108/13598540710737271

Journal of Industrial Engineering and Management, 2017 (www.jiem.org)

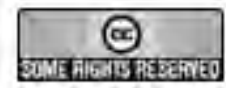

Article's contents are provided on an Attribution-Non Commercial 3.0 Creative commons license. Readers are allowed to copy, distribute and communicate article's contents, provided the author's and Journal of Industrial Engineering and Management's names are included. It must not be used for commercial purposes. To see the complete license contents, please visit http://creativecommons.org/licenses/by-nc/3.0/. 